\title{
EFFECTS OF WATER EMULSIFIED B5-DIESEL AND BIOGAS ON THE COMBUSTION AND EMISSIONS OF RCCI ENGINE AT LOW LOAD
}

\author{
Ibrahim B. Dalha \\ Centre for Automotive Research and Electric Mobility/Universiti Teknologi PETRONAS, \\ 32610 Seri Iskandar Perak, Malaysia, \\ Department of Agricultural and Bio-resources Engineering, Faculty of Engineering/Ahmadu \\ Bello University, 1045 Samaru Zaria, Nigeria \\ Mior A. Said, Z. A. Abdul Karim, and Ezrann Z. Zainal A \\ Centre for Automotive Research and Electric Mobility/Universiti Teknologi PETRONAS, \\ 32610 Seri Iskandar Perak, Malaysia
}

\begin{abstract}
An experiment was conducted to investigate the effects of water in biodiesel emulsions (WiBE) and biogas on the reactivity-controlled compression ignition combustion for improved performance and reduced emissions. $13 \% \mathrm{WiBE}, 15 \% \mathrm{WiBE}$ and regular $B 5$ were, directly, injected with the port injection of biogas at the intake valve, as a modified fueling approach. An advanced injection timing of $21^{\circ} C A B T D C$ and energy fraction of $50 \%$ each of the fuels, were maintained at a speed of $2000 \mathrm{rpm}$ and vary the load from 4.5 to 6.5 bar IMEP. The combustion of WiBE and biogas had been found disadvantageous to the rise in the cylinder pressure and heat released at high load but highly beneficial in reducing peak pressure rise rate besides lowering the in-cylinder temperature as a useful tool for low-temperature combustion technique. The use of WiBE and biogas resulted in a retarded combustion phase while B5 demonstrated more delayed combustion. Both $13 \%$ and $15 \%$ water emulsions exhibited similar carbon dioxide emission attributes but remained higher compared to the regular B5 at all the engine capacity except 6.5 bar IMEP. The fuels reactivity lowers significantly, the in-cylinder temperature causing elevated carbon monoxide (CO) and unburned hydrocarbon (UHC) emissions, by $41.09 \%$ and $19.61 \%$ respectively, along with the reduced nitrogen oxides emission by 50.85\%. Use of strategies to raise the in-cylinder temperature may cut down the challenging emissions.
\end{abstract}

Keywords: biogas, diesel engine, port injection at valve, RCCI combustion, water in biodiesel emulsion.

Cite this Article: Ibrahim B. Dalha, Mior A. Said, Z. A. Abdul Karim, and Ezrann Z. Zainal A. Effects of Water Emulsified B5-Diesel and Biogas on the Combustion and Emissions of RCCI Engine at Low Load. International Journal of Mechanical Engineering and Technology 11(1), 2020, pp. 47-60.

https://iaeme.com/Home/issue/IJMET?Volume=11\&Issue $=1$ 


\section{INTRODUCTION}

A compression ignition (CI) engine excelled because of high fuel efficiency [1] but face challenges of meeting the strict emission standards [2,3]. Sustainability and cleanness of the fuel called for reduced dependence on petroleum-based fuels [4,5]. Biodiesel is among the most promising and attractive alternatives, because of ease of production, handling, and storage [6]. Biodiesel can replace fossil diesel in the internal combustion engine and reduce its harmful emission while retaining the animation-cycle emission of the carbon monoxide (CO) [7]. According to Gashaw et at., [8] direct use of the biodiesel produced from vegetable oils might result in some technical faults, thereby emphasizing the benefit of utilizing the biodiesel in a blended form. Therefore, blends of biodiesel at a $20 \%$ and below, volume-wise, has less detrimental effects on a diesel engine and can be used with no or minor modifications [9]. Some researches that used biodiesel blends reported a decrease in particulate matter with an increase in nitrogen oxides (NOx) emission $[10,11]$. However, the use of water in biodiesel emulsion (WiBE), as an alternative fuel, can cut down the in-cylinder temperature leading to a significant reduction in the NOx emission [12,13]; hence the motivation of the authors to adopting such fuel. Besides, little efforts were devoted to exploring the workability of biogas in RCCI combustion, among which are the studies of Wang et al., [14], Qian et al., [15], and Kakaee et al., [16] with the biogas composition having small percentage of carbon dioxide $\left(\mathrm{CO}_{2}\right)$. The form of biogas studied, also, motivated the authors to investigate the workability of biogas having high $\mathrm{CO}_{2}$ fraction; $75 \%$ methane $\left(\mathrm{CH}_{4}\right)$ and $25 \% \mathrm{CO}_{2}$ by mole. Therefore, utilization of these alternatives along with the advanced combustion technologies, such as low-temperature combustion (LTC), will pave the way for more advances in CI engine.

Recently, the attention of researchers centred on LTC technologies for achieving high efficiency with minimised emissions [17], which is an insight into contemporary combustion technology that combined the principle of the 4-stroke engine and essential processes of the CI and sparked ignition engines [18]. According to Imtenan et al., [19], LTC lowers the peak temperature and drastically reduces the rate of the NOx formation due to the less activation energy of the nitrogen-oxygen bond-forming reactions. Among the LTC techniques is the reactivity-controlled compression ignition (RCCI) combustion [20]. RCCI was remodelled for the in-cylinder blending of two or more fuels of different reactivity, ranging from fossils to biofuels at the liquid or gaseous state, to improve combustion phase and extended load $[1,20]$. The RCCI combustion concept has turned out to be a promising model for the upcoming progeny of internal combustion engines, but still subject to an in-depth study for its perfection [21,22]. Li et al., [1] suggested investigations on the various injection approaches for more control in RCCI combustion. Therefore, the quest for further reduction of UHC and CO emission through a simple to achieve, easy to implement and cost-effective modified port injection approach motivated the research on gaseous low reactivity fuel (LRF) injection at the valve, which aimed at eliminating air-fuel mixing before entering the cylinder and reducing the amount of fuel mixture entering the crevices. Therefore, the paper aimed at investigating the effects of $\mathrm{WiBE}$ and biogas injected at the intake valve, as reactivity fuels, on the combustion and emission attributes of low-temperature RCCI engine at low loads.

\section{EXPERIMENTAL METHODOLOGY}

\subsection{Experimental Set-up and Measurement}

The research was carried out at the Center for Automotive Research and Electric Mobility (CAREM), Universiti Teknologi PETRONAS. A single-cylinder, four-stroke, Yanmar diesel engine was modified to achieve the biogas injection at the valve, as a modified port injection approach. The technical information on the test equipment is presented in Table 1, while Fig. 1 depicted the layout of the engine test rig. An injector holder and a delivery hose were 
developed and coupled to the air intake manifold to enable achievement of the in-cylinder fumigation of the biogas. The biogas was delivered much closed to the air inlet valve attaining nearly zero mixing distance and virtually eliminated the air-fuel mixing before entering the cylinder. The delivery hose was equipped with a gasket at its tip to avoid direct metallic contact and enable biogas fuel flow control using intake valve reciprocation.

The eddy current dynamometer (DW10, 10kw, 50Nm, 13000rpm) was used for the measurement of engine load and speed while a rotary type encoder (E50S8-360-3-T-24) was utilized for the crank angle measurement. The engine used a pressure transducer to detect the pressure inside the cylinder. A hot-wire airflow meter was used to measure the airflow rate, range: $0-30 \mathrm{~m} / \mathrm{Sec}$, and a pressure sensor, range: $-1-1 \mathrm{bar}$, was also used for the air pressure measurement. A $\mathrm{K}$ - type thermocouple, $0-1100^{\circ} \mathrm{C}$ ranges was employed to measure the air temperature. The information on the B5-diesel mass flow rate and volume were obtained from the data acquisition system through a weighing scale attached to the engine control unit. However, a Linde HiQ pressure regulator was incorporated to decompress the biogas pressure to 2 bar, and its mass flow rate was measured using IGO8 R3 Concoa gas flow meter. Also, an SPTC AutoChek gas analyzer (M-GS-V1.5EIC) was used to measure NOx, CO, unburned hydrocarbon (UHC), $\mathrm{CO}_{2}$, and oxygen gas $\left(\mathrm{O}_{2}\right)$ emissions with an accuracy of 1ppm, 1ppm $0.01 \%, 0.01 \%$, and $0.01 \%$ respectively. A mechanical blender was used for the manual blending while Hielscher Ultrasonic Processor (UP100H) was used for the ultrasonic mixing.

Table 1: The technical specification of the test equipment (engine)

\begin{tabular}{lll}
\hline \multicolumn{1}{c}{ Description } & \multicolumn{1}{c}{ Specifications } \\
\hline Model & L100V \\
Type & Single cylinder, 4-stroke, air-cooled engine \\
Bore & $86 \mathrm{~mm}$ \\
Stroke & $75 \mathrm{~mm}$ & \\
Displacement & $0.435 \mathrm{liters}$ & \\
Compression ratio & $20.0 \pm 0.3$ & \\
Fuel injection timing & $21^{\circ}$ CA BTDC & $3600 \mathrm{rpm}$ \\
Continuous Rate Output & Engine speed & $6.2 \mathrm{~kW}$ \\
& Output & $3600 \mathrm{rpm}$ \\
Maximum Rated Output & Engine speed & $6.8 \mathrm{~kW}$ \\
\hline
\end{tabular}

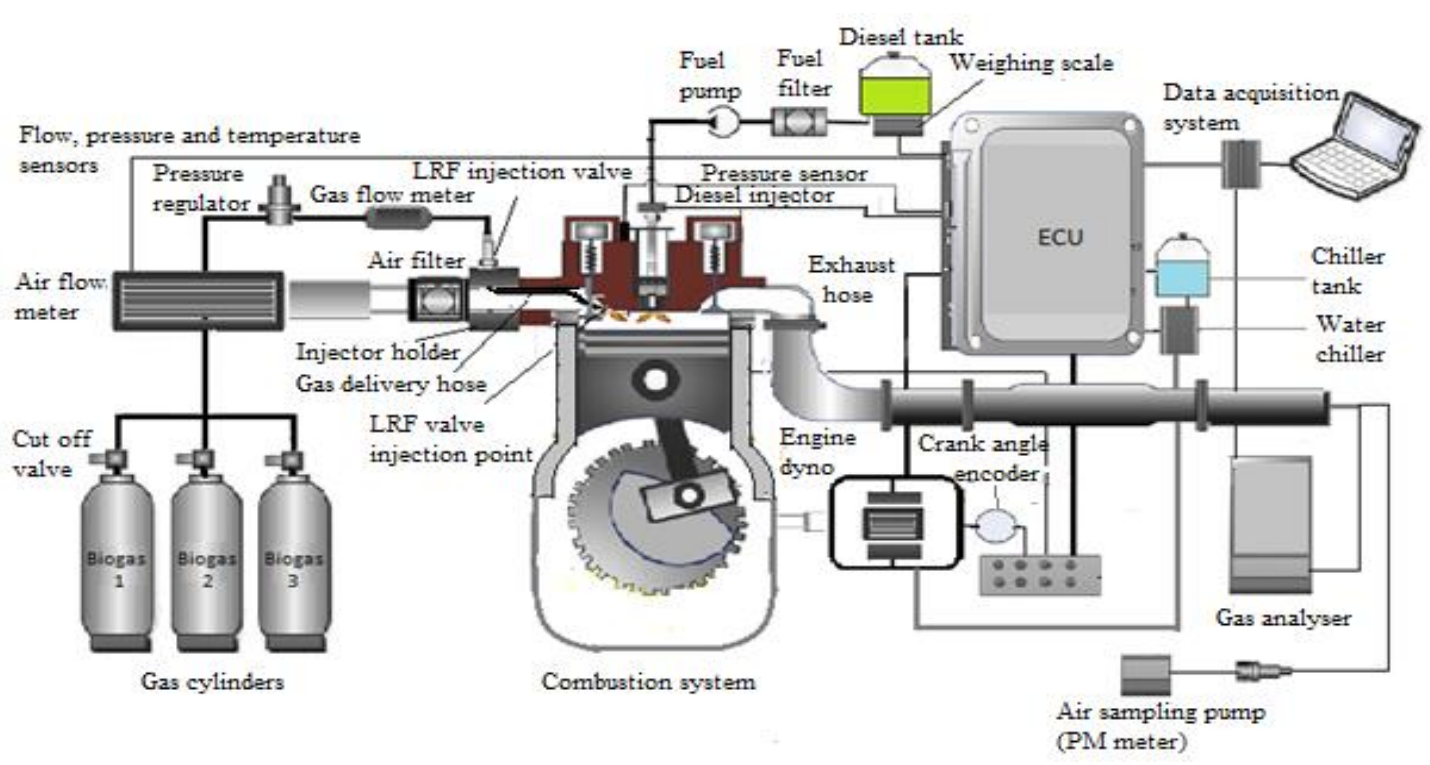

Figure 1: An illustration of the engine test rig 


\subsection{Experimental Procedure}

The test was conducted to investigate the engine characteristics at high speed and low load (4 -7 bar IMEP) conditions in a modified approach of port injection at the valve. A consistent engine speed of $2000 \mathrm{rpm}$ was considered based on the manufacturer's recommendation and varied the load from the no-load indicated mean effective pressure (4.5 bar IMEP) to a maximum achievable capacity of 6.5 bar IMEP at an interval of 0.5 bar IMEP. The research reported the engine capacity based on the actual indicated mean effective pressures (IMEP) to reflect the low load range, unlike the usual load percentages. A test was carried out to determine the appropriate proportions of the dynamometer brake applied and throttle position to achieve the average IMEP corresponding to the percentage increase in the load for each of the high reactivity fuels (HRF) at speed selected. Table 2 shows the detailed engine loading with the corresponding percentages of the dynamometer brake applied and throttle position for the WiBE and B5 fuels at a speed of $2000 \mathrm{rpm} .13 \%$ and 15\% WiBE were injected directly as pilot fuels while the regular B5 was considered as a reference. The amount of fuel directly injected at every load level was preliminarily estimated to maintain a fraction of $50 \%$ for each of the directly injected fuel used, as presented in Table 2. An advanced injection timing of $21^{\circ} \mathrm{CA}$ BTDC was considered because early direct injection timing improves the incylinder mixing and fuel combustion at low load [23,24]. A nearly zero mixing distance from the valve position was considered for the approach of injection at the valve. Comparatively, Fig. 2 shows the conventional premixed port injection and the port injection at the valve for this research. The biogas fuel was delivered at a constant pressure of 2 bar while its flow rate was varied with the engine load to ensure a 50\% biogas energy fraction. The in-cylinder temperature developed was estimated using thermoduynamic equation at each crank angle degree; thus, enabled determination of the maximum in-cylinder temperature at its corresponding crank angle degree.

Table 2: Estimated test parameters, on average, at various load capacities

\begin{tabular}{|c|c|c|c|c|c|c|c|c|c|}
\hline \multicolumn{3}{|c|}{ Engine load } & \multicolumn{2}{|c|}{ WiBE at 2000 rpm } & \multicolumn{2}{|c|}{ B5 at 2000 rpm } & \multicolumn{2}{|c|}{ HRF mass } & \multirow{2}{*}{$\begin{array}{c}\mathrm{LRF} \\
\text { mass } \\
(\mathrm{g})\end{array}$} \\
\hline$(\%)$ & $\begin{array}{c}\text { (bar } \\
\text { IMEP) }\end{array}$ & SD & Brake $(\%)$ & $\begin{array}{c}\text { Throttle } \\
(\%)\end{array}$ & $\begin{array}{c}\text { Brake } \\
(\%)\end{array}$ & $\begin{array}{c}\text { Throttle } \\
(\%)\end{array}$ & (g) & SD & \\
\hline 0 & 4.483 & \pm 0.075 & 24 & 54 & 23 & 53 & 0.0181 & \pm 0.0066 & 0.0181 \\
\hline 25 & 4.955 & \pm 0.086 & 37 & 55 & 36 & 55 & 0.0256 & \pm 0.0058 & 0.0256 \\
\hline 50 & 5.582 & \pm 0.063 & 55 & 57 & 56 & 57 & 0.0347 & \pm 0.0051 & 0.0347 \\
\hline 75 & 6.107 & \pm 0.056 & 75 & 60 & 74 & 60 & 0.0408 & \pm 0.0073 & 0.0408 \\
\hline 100 & 6.578 & \pm 0.078 & 93 & 61 & 91 & 62 & 0.0499 & \pm 0.0021 & 0.0499 \\
\hline
\end{tabular}

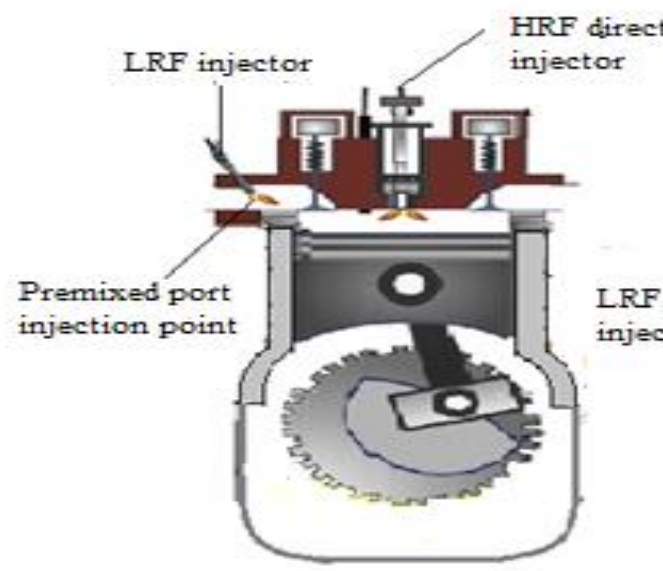

(a)

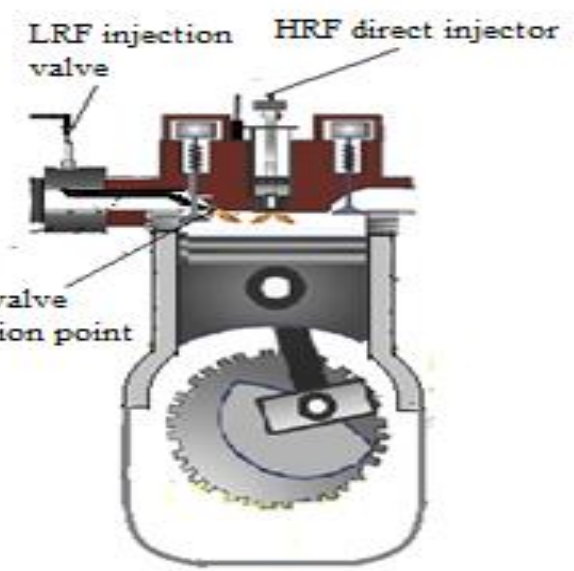

(b)

Figure 2: a) Conventional premixed port injection b) port injection at the valve 


\subsection{Test Fuels}

This research investigated the performance of WiBE, which is B5 diesel containing 13 and $15 \%$ emulsified water, in RCCI mode, as direct-injected pilot fuel. Table 3 presented the specifications, and some properties of the WiBE used. The $13 \%$ and 15\% WiBE were selected based on the outcome of previous research activities carried out at CAREM to evaluate the use of $\mathrm{WiBE}$ as an emission reduction technique in a diesel engine; thus, adopted for evaluation in RCCI mode. The B5-diesel, used as a reference, is commercially available at Petron stations in Malaysia. The research uses low-quality biogas, as port-injected LRF, which composed of $75 \% \mathrm{CH}_{4}$ and $25 \% \mathrm{CO}_{2}$ by mole, to simulate biomass-based biogas fuel. The biogas fuel was obtained from a gas company, Linde Malaysia. Table 4 presented some properties of the simulated biogas and B5-diesel used. To the best of the authors' knowledge, this article is the first to report the use of these fuels with the approach of biogas injection at the valve.

Table 3: Specifications and some properties of the WiBE used

\begin{tabular}{lcc}
\hline \multicolumn{1}{c}{ Properties } & \multicolumn{2}{c}{ Specifications } \\
\hline Emulsion & $13 \%$ WiBE & $15 \% \mathrm{WiBE}$ \\
Water $(\%)$ & 13 & 15 \\
HLB Values & 7 & 8 \\
Surfactant dosage $(\%)$ & 7 & 9 \\
Density at $25^{\circ} \mathrm{C}(\mathrm{g} / \mathrm{ml})$ & 0.8566 & 0.8552 \\
Viscosity $\left(\mathrm{mm}^{2} / \mathrm{s}\right)$ & 8.265 & 8.265 \\
SMD Values $(\mu \mathrm{m})$ & 3.066 & 3.086 \\
Blending method & Ultrasonic & Mechanical \\
\hline
\end{tabular}

Table 4: Characteristics of the fuels used for the test

\begin{tabular}{lcc}
\hline \multicolumn{1}{c}{ Properties } & Biogas & B5 Diesel \\
\hline Density $\left(\mathrm{kg} / \mathrm{m}^{3}\right)$ & 1.353 & 823.45 \\
Lower flammability limit $(\mathrm{mol} \%)$ & $6.1-22.4$ & $0.75-4.6$ \\
Molecular weight $(\mathrm{g} / \mathrm{mol})$ & 23.5132 & 174 \\
Specific gravity at $0^{\circ} \mathrm{C}$ & 1.05 & 0.852 \\
Specific volume $\left(\mathrm{m}^{3} / \mathrm{kg}\right)$ & 0.739 & \\
Kinematic viscosity $(\mathrm{cSt})$ & 12.74 & $1.5-5.8$ \\
Lower heating value $(\mathrm{MJ} / \mathrm{m} 3)$ & 26.24 & \\
Stoichiometric air-fuel ratio & $4.56: 1$ & $14.97: 1$ \\
\hline
\end{tabular}

\section{RESULTS AND DISCUSSION}

\subsection{Effects of Water Emulsification on the Combustion Characteristics}

\subsubsection{Influence on the cylinder pressure traces}

The pressure traces, for the combustion of WiBE and biogas injected at the valve, varies with the engine loads and indicated a pattern of two peaks with the maximum pressure developed at the first peak for higher IMEP. Fig. 3(a) depicted that the second peak rises with the increase in the IMEP for the burning of $15 \% \mathrm{WiBE}$ and biogas injected at the valve. The combustion of $13 \% \mathrm{WiBE}$ and biogas exhibited similar trends as the IMEP increases, as shown in Fig. 3(b). Both Fig. 3(a) and 3(b) indicated an insignificant peak at the second phase of the pressure development for the 4.5 and 5 bar IMEP. The second peak development occurred during expansion, as the period in which most of the heat generated could be due to the burning of LRF in the RCCI combustion. It signifies that the decrement in the pressure at the second peak could due to less heat generated because of the burning effect of the biogas 
fuel at low IMEP. The amount of biogas burned increases as more of the fuel was injected at higher IMEP causing elevated pressure, though maintained relatively the same fraction. Besides, the water content in $\mathrm{WiBE}$, also, influences the rate of the pressure development at the second peak, as Fig. 3(c) shows that $15 \%$ WiBE has higher in-cylinder pressure at the second peak compared to the $13 \% \mathrm{WiBE}$ for the maximum load of 6.5 bar IMEP. According to Fig. 3(a) and 3(b), the maximum in-cylinder pressure developed at first peak, during the combustion of WiBE along with the biogas, was relatively independent of the change in engine load; hence could be due to the burning of WiBE. However, Fig. 4(a) depicted that the burning of $13 \% \mathrm{WiBE}$ resulted in higher maximum pressure at the lower capacity $(4.5-5$ bar) IMEP, unlike $15 \% \mathrm{WiBE}$ which superseded at higher engine capacities. The variation could be due to the homogeneity of the ultrasonically blended $13 \%$ WiBE, which had more effect on the flammability of the mixture causing a rise in the pressure at the first peak. A $15 \% \mathrm{WiBE}$, which was mechanically blended, has higher water concentration and broader droplet distribution that facilitate the formation of more reactivity pockets of the B5. These pockets enabled more spontaneous ignition that helps to evaporate the water and reduces the pressure build-up due to the water content. According to Khan [25], the pressure rises in the cylinder due to ignition delay caused as a consequence of water emulsion. To support these reasons, the combustion of non-emulsified B5 and biogas, injected at the valve, developed less in-cylinder maximum pressure.

Another critical aspect of these fuels reactivity is the low peak pressure rise rate (PPRR), as shown in Fig. 4(b). The use of WiBE and biogas injected at the valve demonstrated an acceptable level of PPRR likely because of low in-cylinder temperature developed. The results showed a maximum of about 2.26 bar/CA, using 15\% WiBE and biogas at full engine capacity, which was approximately $43.5 \%$ lower than the standard Euro IV limit for the lightduty diesel engine. The less PPRR of the WiBE and biogas reactivity was found comparable to that of the regular B5, which implies that use of biogas as LRF might be a reason for such benefit.
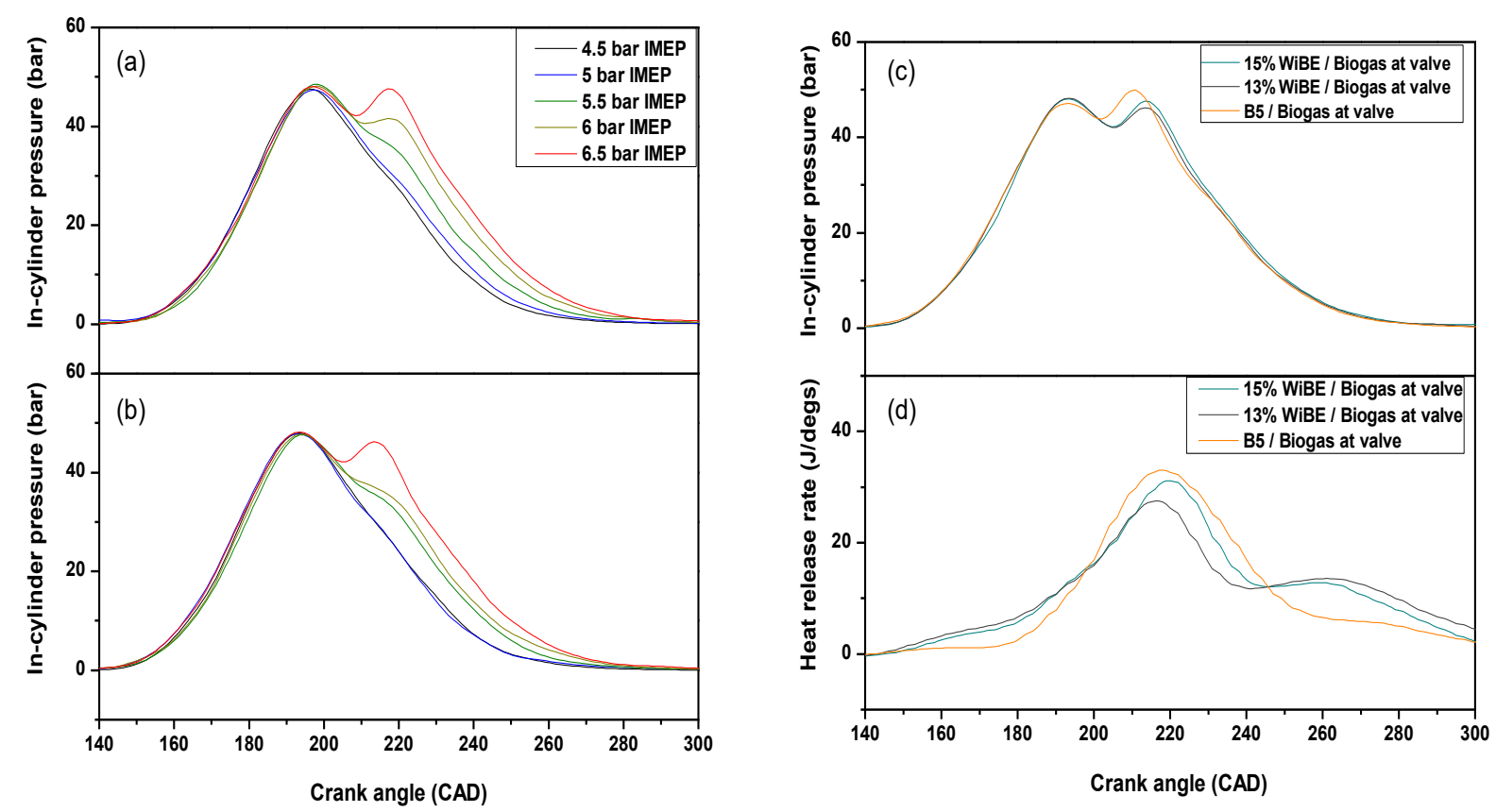

Figure 3: In-cylinder pressure traces for the RCCI combustion of; (a) 15\% WiBE/Biogas (b) 13\% WiBE/Biogas (c) HRF/Biogas at 6.5 bar IMEP and (d) heat release rate for the HRF/Biogas at 6.5 bar IMEP 


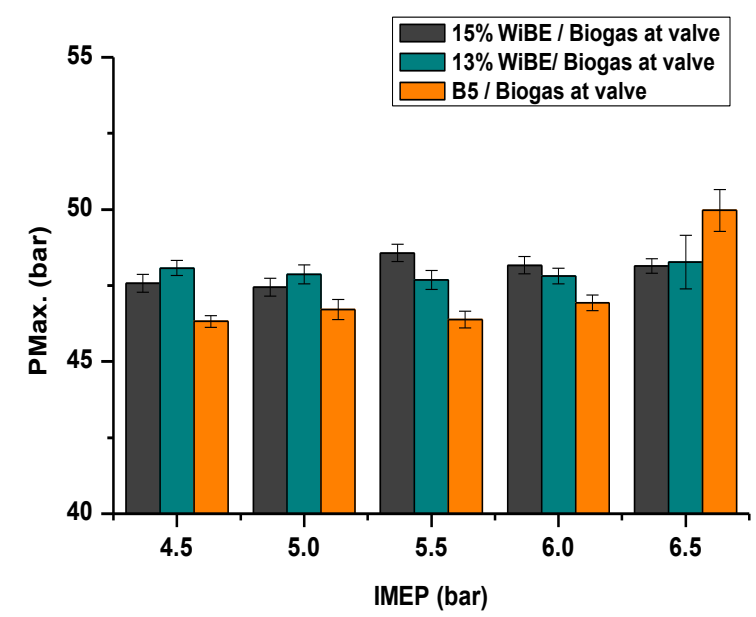

(a)

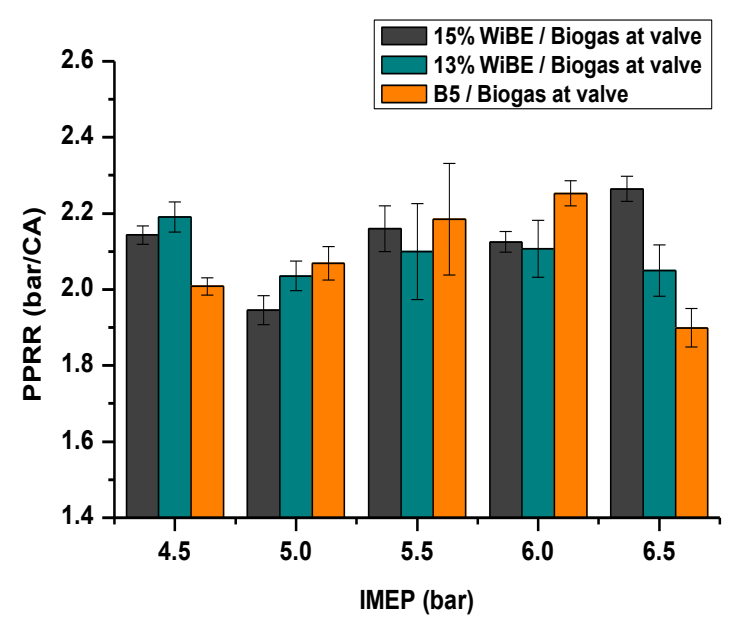

(b)

Figure 4: Variation of; (a) maximum in-cylinder pressure (PMax.) and (b) peak pressure rise rate (PPRR), for the WiBE and conventional B5/biogas RCCI combustion.

\subsubsection{Influence on the Rate of Heat Released}

Fig. 3(d) above showed an identical pattern of heat release rate (HRR) for $13 \%$ and $15 \%$ WiBE at a maximum 6.5 bar IMEP, though $15 \%$ WiBE demonstrated higher HRR during the expansion stroke. Observed was a similar attribute for the rest of the engine capacities. Besides, the figure further showed that the heat generated by the combustion of both $13 \%$ and $15 \%$ WiBE along with the biogas injected at the valve was, virtually, less compared to the burning of regular B5 and biogas injected at the intake valve, because of the cooling effect of the water emulsion. As also observed in Fig. 5(a), the combustion of the 15\% WiBE and biogas virtually demonstrated more heat release at all the load capacities, compared to that of $13 \% \mathrm{WiBE}$. The heat release increased as the load increases from 4.5 bar IMEP to 5.5 bar IMEP and proceeds accordingly with a little drop at a load of 6 bar IMEP. Nevertheless, the WiBE showed lower total HRR compared to the regular B5 and biogas injected at the intake valve, which could be related to either specific heat value of the WiBE or cooling effects of the water emulsion.

\subsubsection{In-Cylinder Temperature Attributes}

Fig. 5(b) showed that the maximum in-cylinder temperature, for the combustion of WiBE and biogas injected at the valve, gradually increased with the increase in the engine capacity. The rise in temperature could be an attribute of the increased quantity of fuel at higher load capacity, though maintained relatively the same energy fraction. According to Fig. 5(b), 15\% WiBE generated more temperature across the various engine capacities, compared to the $13 \%$ WiBE, because of the higher water content or heterogeneity of the emulsion which allows the formation of more B5 reactivity pockets and subsequently develops more temperature. Another reason could be the higher density of the WiBE, which might affect the flammability of the mixture. The use of WiBE in reactivity with the biogas takes the in-cylinder temperature much lower than $2000 \mathrm{~K}$. This attribute makes it a useful tool for lowtemperature combustion, though associated with a lot of disadvantages that are subject to further effort for proper utilization. 


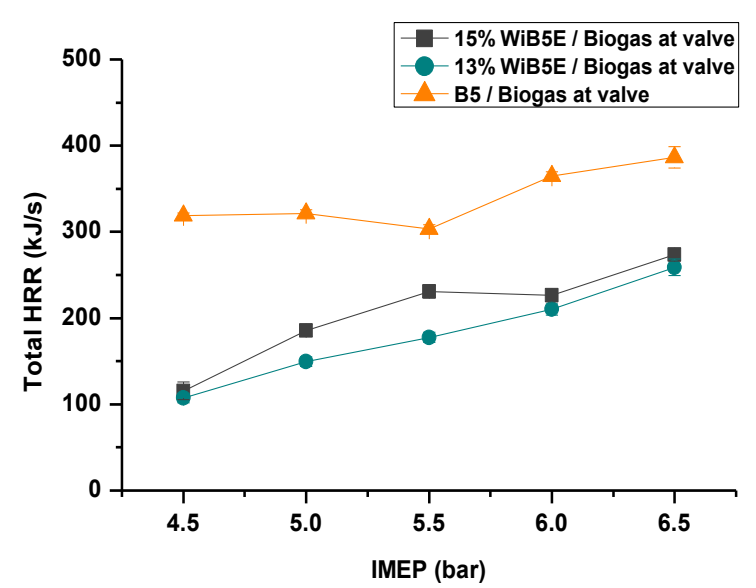

(a)

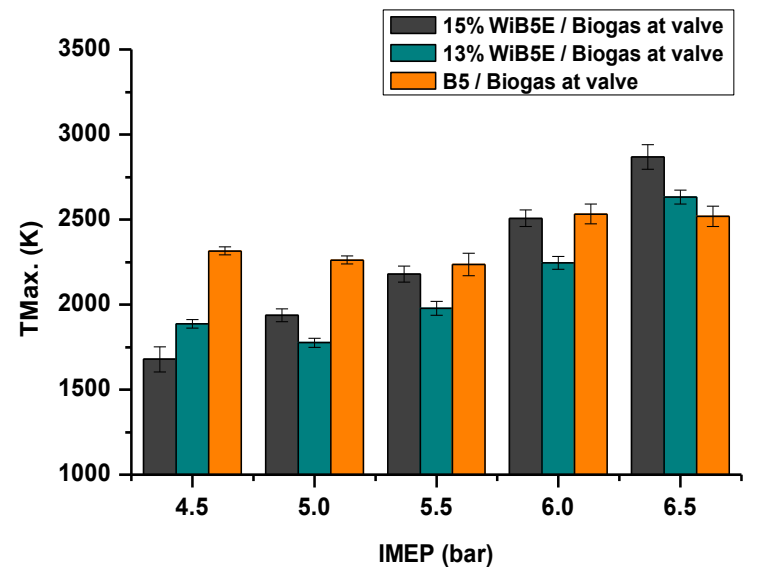

(b)

Figure 5: Variation of; (a) total heat release rate (HRR) and (b) maximum in-cylinder temperature (TMax.), for the RCCI combustion of WiBE/biogas at various engine capacities.

\subsubsection{Influence on the Combustion Dynamism}

Combustion phase (CA50) was examined, as the period when $50 \%$ of the fuel burned, to have more understanding of the combustion attributes of these fuels. Based on the information from Fig. 6(a), the combustion of $15 \% \mathrm{WiBE}$ and biogas injected at the valve demonstrated a retarded combustion phase as the engine capacity increases, unlike the 13\% WiBE which shows an advance, as the engine capacity increases from 4.5 to 5.5 bar IMEP then retarded as it proceeds to 6.5 bar IMEP capacity. The delay in the combustion might be caused by the atomization of the direct-injected emulsified fuel as similarly observed by Wang et al., [14]. According to Albert [25], the vaporization time required, prior to ignition, maight be a cause of delay in CI combustion. Fig. 6(c) and 6(d) showed the analytical trends for the burning of $13 \%$ and $15 \%$ WiBE along with the biogas. As seen, both $13 \%$ and $15 \%$ WiBE shows combustion phase at the same crank angle position under 4.5 bar IMEP, but the slowness of the combustion manifested more with the use of $15 \% \mathrm{WiBE}$ as the engine capacity extends to a maximum of 6.5 bar IMEP. A similar trend was observed during combustion of the regular B5 but indicated more delayed combustion phase at every IMEP, likely because of the higher quantity of more reactive mixture in the cylinder which might extend the burning duration. This reason manifested in the trends of the burning duration of the $15 \% \mathrm{WiBE}$ and regular B5, as shown in Fig. 6(b). However, the pattern of 13\% WiBE shows more extended burning duration with the early combustion phase, at an engine capacity of 6 bar IMEP, likely because the burning of the first half of the mixture was faster compared to the remaining half. The difference in the burning duration could also be an influence of the mixture quality relative to the reactivity of the fuels along with the biogas injection at the valve. Comparatively, Wang et al., [14] reported lesser burning duration, which could be due to the fuel quality that, the biogas used in the said report composed of hydrogen gas, which might facilitate faster burning. 
Effects of Water Emulsified B5-Diesel and Biogas on the Combustion and Emissions of RCCI Engine at Low Load
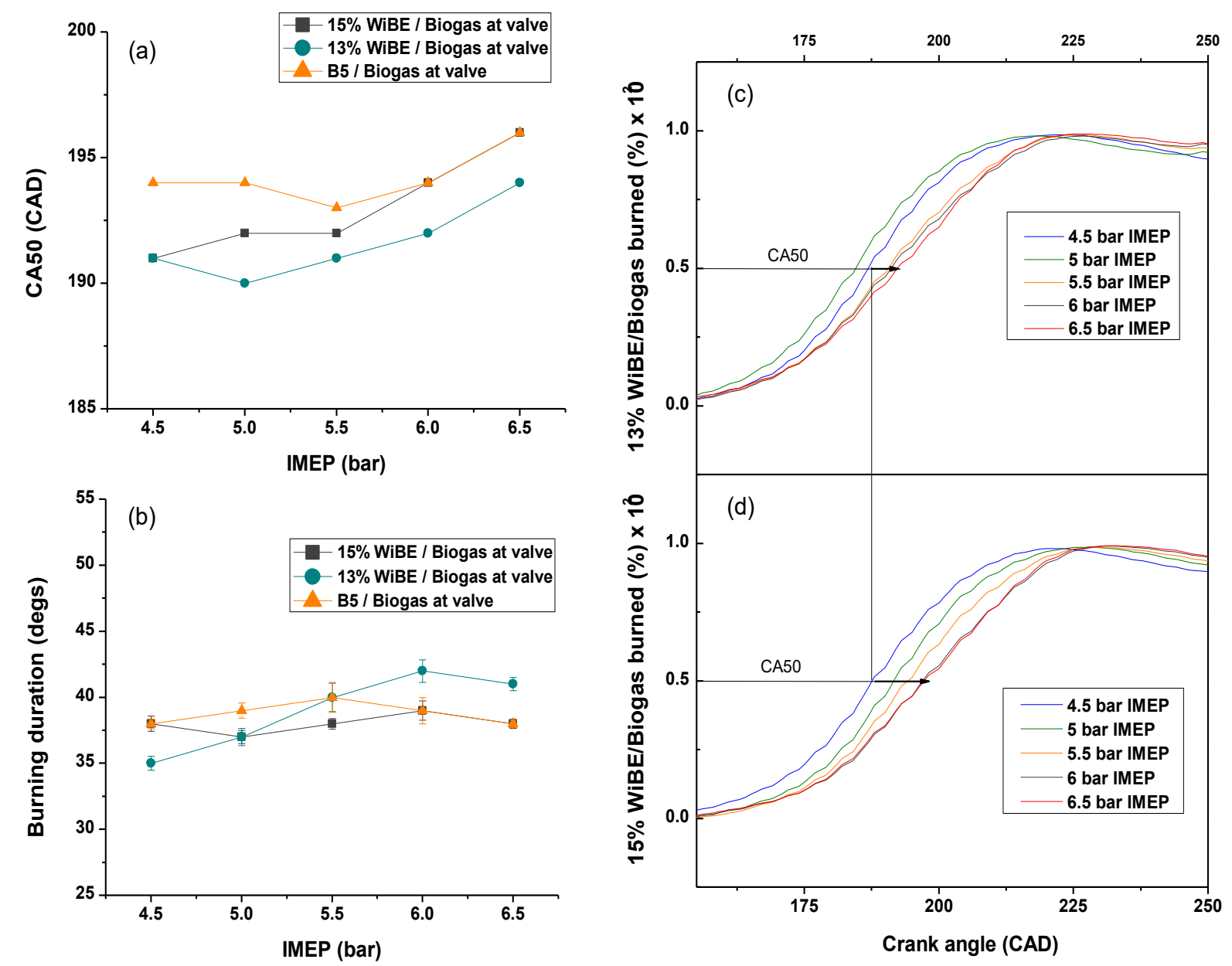

Figure 6: Variation of; (a) combustion phase (CA50), (b) burning duration and (c) dynamism of the fuel fraction burned and combustion phase for the RCCI combustion of WiBE/biogas.

\subsection{Effects of Water Emulsification on the Emission Characteristics}

\subsection{1. $\mathrm{CO}_{2}$ emission}

$\mathrm{CO}_{2}$ is an essential emission parameter in this study because the simulated biogas used, composed of $25 \% \mathrm{CO}_{2}$ by mole. According to Fig. 7(a), the $\mathrm{CO}_{2}$ emission increased as the engine capacity increases, for the combustion of both $13 \%$ and $15 \% \mathrm{WiBE}$ along with the biogas injected at the valve, because of the rise in the amount of the non-combustible $\mathrm{CO}_{2}$ concentration in the fuel burned as the engine capacity increases. Besides, Ithnin et al., [26] reported a similar trend for the conventional water in diesel combustion and explained that the rise in the $\mathrm{CO}_{2}$ emission is an indication of the increase in combustion efficiency. Fig. 7(a) further shows that the burning of WiBE for both $13 \%$ and $15 \%$ water content exhibited relatively similar $\mathrm{CO}_{2}$ emission attributes but remained higher compared to the conventional B5 at all the engine capacities except 6.5 bar IMEP. The WiBE rises the $\mathrm{CO}_{2}$ emission, averagely, by $5.35 \%$. At 6.5 bar IMEP, the $\mathrm{CO}_{2}$ emission of the traditional $\mathrm{B} 5$ elevated higher to outweigh the discharge of the $15 \%$ emulsion. The discrepancies were because, the combustion of the $\mathrm{WiBE}$ and biogas resulted in much lower in-cylinder temperature, as shown in Fig. 5(b) above, which influences a slow conversion process and high $\mathrm{CO}_{2}$ production in a thermochemical process involving gaseous fuel [27]. Fig. 5(b) shows that the margin of the in-cylinder temperature between the WiBE and non-emulsified B5 decreases 
with the increase in the engine capacity and non-emulsified B5 generated the highest temperature at 6.5 bar IMEP; hence its $\mathrm{CO}_{2}$ discharge tends to elevate more at this load level.

\subsubsection{CO emission}

As presented in Fig. 7(b), the combustion of WiBE and biogas injected at the valve demonstrated a trend of decrease in $\mathrm{CO}$ emission, as the engine capacity increases, for the $15 \%$ emulsion. The reduction in the $\mathrm{CO}$ emission was more significant at 5.5 to 6.5 bar IMEP. However, the combustion of a $13 \%$ emulsion resulted in an insignificant increase in the CO emission from 4.5 to 5.5 bar IMEP then decreases as the engine capacity increases to 6.5 bar IMEP. Fig. 5(b) indicated a decrease in the in-cylinder temperature, as the engine capacity increases, for the combustion of WiBE, which might be the reason for the decline in the CO emission. Generally, the use of WiBE lowers, significantly, the in-cylinder temperature causing elevated CO emission, approximately by $41.09 \%$, compared to the non-emulsified B5. In-cylinder pressure, ignition delay, and equivalence ratio might also have effects on the $\mathrm{CO}$ emission [28]. Although, the impact of in-cylinder mixing, as an attribute of injection at the valve, also elevated the in-cylinder temperature, which might have increased the rate of $\mathrm{CO}$ oxidation; hence contribute to reducing the rate of $\mathrm{CO}$ emission. Similarly, the combustion of the non-emulsified B5 indicated an apparent increase in the CO emission from 4.5 to 5.5 bar IMEP then decreases as the engine capacity increases to 6.5 bar IMEP, which could be attributable to the pattern of the in-cylinder temperature developed as shown in Fig. $5(b)$.

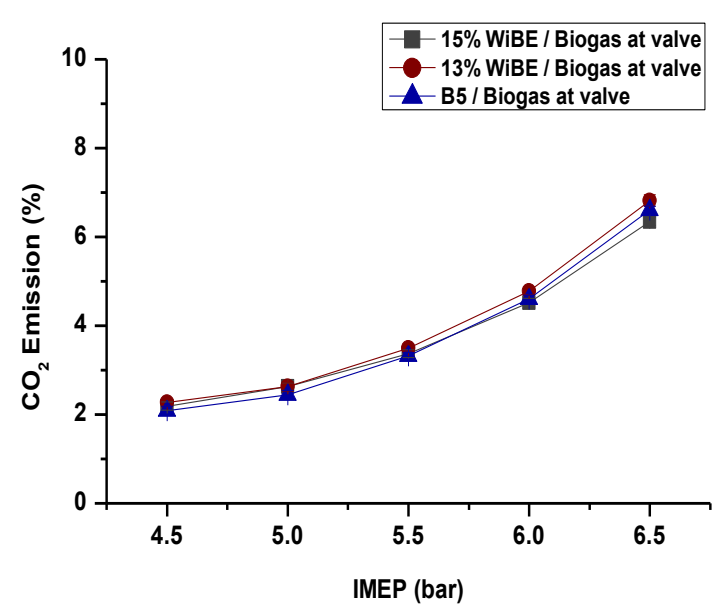

(a)

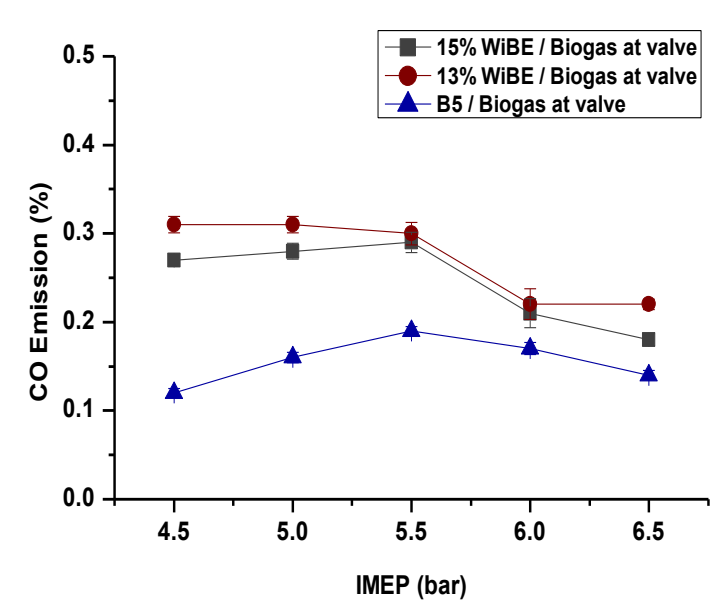

(b)

Figure 7: Engine-out (a) $\mathrm{CO}_{2}$ emission and (b) $\mathrm{CO}$ emission for the RCCI combustion of WiBE and biogas injected at the valve.

\subsubsection{UHC emission}

Fig. 8(a) revealed that the UHC emission, for the WiBE and biogas injected at the valve, was high at the no-load condition and increased as the capacity increases to 5 bar IMEP then decreased, gradually, as the capacity proceeds to 6.5 bar IMEP. The cause of the decrease in the UHC emission might likely be an influence of either increase in the in-cylinder temperature, which might increase the rate of the fuel burned or fewer amounts of the fuel entering the crevices [29], as contributed by the injection at the valve approach. Debnath et al., [30] reported a contrary trend and explained that the high UHC emission observed at low load was due to an insufficient temperature to burn the fuel while insufficient air was the reason for the high UHC emission at the higher capacity. The combustion of the WiBE and biogas emitted more UHC compared to that of the regular B5, but 13\% emulsion discharged higher UHC across the engine capacity due to less in-cylinder temperature developed at every 
IMEP because of more homogeneity of the emulsion, which reduces the global reactivity of the mixture. The WiBE was found to elevate the UHC emission approximately by $19.61 \%$ compared to the regular B5. The impact of the in-cylinder mixing, as a consequence of injection at the valve, reduced the uniformity of the air-fuel mixture in the cylinder and enabled the air to occupy the crevice regions; hence contribute to reducing the rate of UHC emission.

\subsubsection{NOx emission}

The effects of water emulsification on the in-cylinder temperature reduction, due to vaporisation, served a significant advantage in cutting down the NOx emission across the engine capacity, as depicted in Fig. 8(b). Dissociation of oxygen atom during ionization of water to form hydroxyl radicals could be another reason for NOx emission reduction. According to Fig. 9(b), the NOx emission, for the combustion of WiBE and biogas, increased with the increase in the engine capacity irrespective of the water concentration used. Similarly, the burning of the non-emulsified B5 and biogas injected at the valve demonstrated the same pattern but emitted more of the NOx emission across the engine capacity, compared to the use of WiBE. The effect of the water emulsification for NOx emission reduction was more pronounced at the higher engine capacity. The analysis of the NOx emission reduction due to the effects of water emulsification shows a significant decrease by approximately $50.85 \%$ compared to the regular B5.

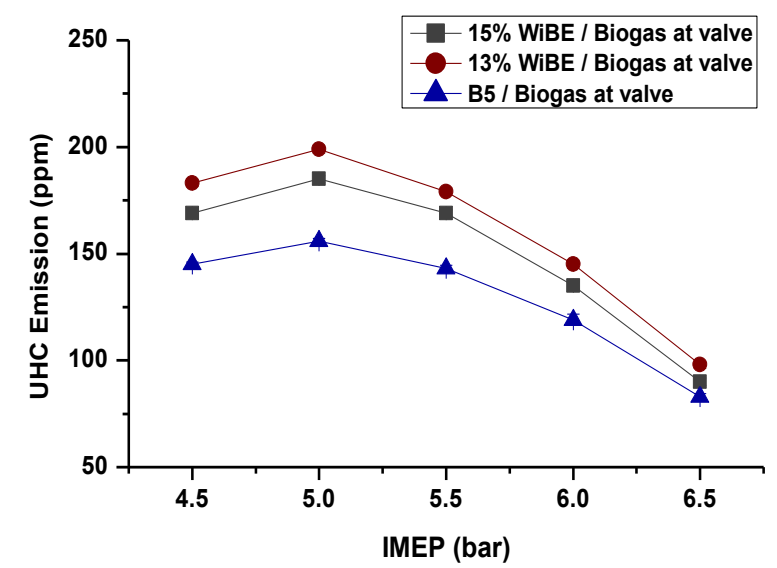

(a)

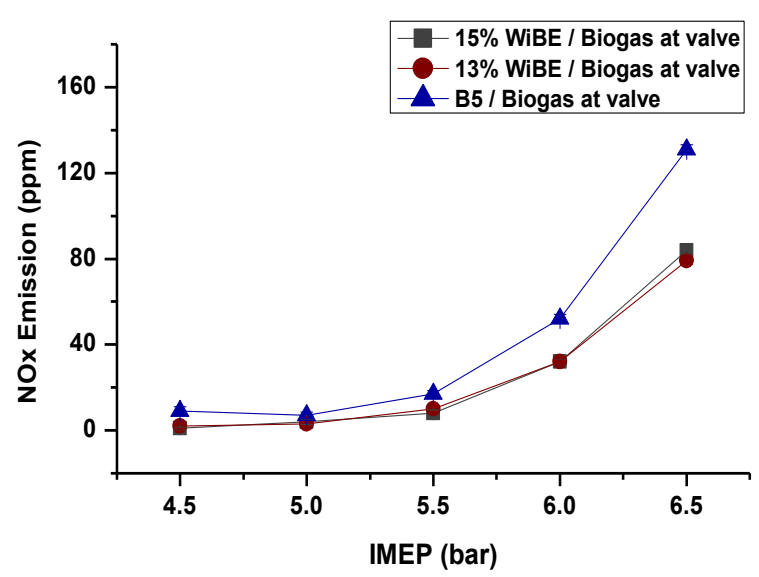

(b)

Figure 8: Engine-out; (a) UHC emission and (b) NOx emission for the RCCI combustion of WiBE and biogas injected at the valve.

\subsection{Discussion}

As observed from the results, the use of $\mathrm{WiBE}$, irrespective of the water concentration, in reactivity with the biogas injected at the intake valve reduces the in-cylinder pressure at low engine capacity, especially the second peak which was due to less heat generated because of the burning effect of the biogas fuel at low IMEP. The use of the fuels demonstrated an acceptable level of PPRR likely because of low in-cylinder temperature developed. However, the use of $15 \% \mathrm{WiBE}$ and biogas at 6.5 bar IMEP reduces the PPRR by approximately $43.5 \%$ lower than the standard Euro IV limit for the light-duty diesel engine. Although the use of $\mathrm{WiBE}$ and biogas is disadvantageous to the rise in the cylinder pressure and heat released but had been found highly beneficial in reducing PPRR besides lowering the in-cylinder temperature as a useful tool for LTC advancement. The combustion of the fuels demonstrated a retarded combustion phase as the engine capacity increases, but the slowness of the burning 
manifested more with the use of $15 \% \mathrm{WiBE}$ at mid to higher IMEP. A similar trend was observed during combustion of the regular B5 but indicated more delayed combustion phase at every IMEP, which implies that the use of WiBE has a significant influence on advanced combustion duration and its magnitude.

Nevertheless, the effects of $\mathrm{WiBE}$ on the in-cylinder temperature reduction, due to vaporisation, served a significant advantage in cutting down the NOx emission across the engine capacity. Unfortunately, the use of WiBE lowers, significantly, the in-cylinder temperature causing elevated $\mathrm{CO}$ and UHC emissions that are currently the setbacks of the RCCI combustion advancement. In summary, the use WiBE in reactivity with the biogas has been found beneficial to lowering the cylinder temperature and PPRR with the advanced combustion phase besides significant reduction in NOx emission approximately by $50.85 \%$. On the other hand, it reduces the cylinder pressure at high load and the amount of heat released besides a considerable rise in the $\mathrm{CO}$ and UHC emissions approximately by $41.09 \%$ and $19.61 \%$, respectively, across the engine capacities.

\section{CONCLUSION}

The combustion of $\mathrm{WiBE}$ and biogas had been found disadvantageous to the rise in the cylinder pressure and heat released at high engine capacity but highly beneficial in reducing PPRR besides lowering the in-cylinder temperature as a useful tool for LTC technique. The WiBE and biogas reactivity resulted in a retarded combustion phase while B5 demonstrated more delayed combustion. Irrespective of the water concentration used, the $\mathrm{CO}_{2}$ emission attributes of the WiBE remained higher compared to the regular B5 at all the engine capacities except 6.5 bar IMEP. The use of WiBE lowers, significantly, the in-cylinder temperature causing elevated CO and UHC emissions, approximately by $41.09 \%$ and $19.61 \%$ respectively, along with the reduced NOx emission approximately by $50.85 \%$, compared to the regular B5; thus, use of some strategies to rise the in-cylinder temperature may serve to reduce the challenging $\mathrm{CO}$ and UHC emissions while advancing the combustion phase.

\section{ACKNOWLEDGEMENTS}

The authors would like to acknowledge the support given by the Universiti Teknologi PETRONAS (UTP) and Centre for Automotive Research and Electric Mobility (CAREM) in conducting this research.

\section{REFERENCES}

[1] J. Li, W. Yang, and D. Zhou, Review on the management of RCCI engines, Renewable and Sustainable Energy Reviews, 69 (May 2016), 2017, 65-79.

[2] H. Kyu and C. Sik, A review on atomization and exhaust emissions of a biodiesel-fueled compression ignition engine, Renewable and Sustainable Energy Reviews, 58, 2016, $1601-1620$.

[3] N. Kumma, R. K. Gopidesi, T. R. Rao, K. M. Kumar, and S. R. Premkartikkumar, Experimental investigation on diesel engine fuelled with hythane gas, International Journal of Mechanical Engineering and Technology, 10 (2), 2019, 571-575.

[4] Z. Zhang and R. Balasubramanian, Effects of oxygenated fuel blends on carbonaceous particulate composition and particle size distributions from a stationary diesel engine, Fuel, 141, 2015, 1-8.

[5] M. V. Rao and K. Simhadri, Experimental investigation on performance characteristics of four stroke single cylinder petrol engine using a pre-heating set-up for methanol blends, International Journal of Mechanical Engineering and Technology, 10 (2), 2019, 351-360. 
[6] P. Geng, E. Cao, Q. Tan, and L. Wei, Effects of alternative fuels on the combustion characteristics and emission products from diesel engines: A review, Renewable and Sustainable Energy Reviews, 71, (December 2016), 2017, 523-534.

[7] V. K. Shahir, C. P. Jawahar, and P. R. Suresh, Comparative study of diesel and biodiesel on CI engine with emphasis to emissions - A review, Renewable and Sustainable Energy Reviews, 45, 2015, 686-697.

[8] A. Gashaw, T. Getachew, and A. Teshita, A review on biodiesel production as alternative fuel, Journal of Forest Product and Industries, 4 (2) 2015, 80-85.

[9] P. Saxena, S. Jawale, and M. H. Joshipura, A review on prediction of properties of biodiesel and blends of biodiesel, Procedia Energy, 51 (NUiCONE 2012), 2013, 395-402.

[10] J. Benajes, S. Molina, A. García, and J. Monsalve-Serrano, Effects of direct injection timing and blending ratio on RCCI combustion with different low reactivity fuels, Energy Conversion and Management, 99, 2015,193-209.

[11] J. Li, W. M. Yang, and D. Z. Zhou, Modeling study on the effect of piston bowl geometries in a gasoline/biodiesel fueled RCCI engine at high speed, Energy Conversion and Management, 112, 2016, 359-368.

[12] P. S. Kumar, B. Venkatesh, B. Rajeswari, V. L. Reddy, S. P. S. Khan, Emission control by using water emulsified diesel, International Journal of Advances in Engineering and Technology, 5 (2), 2013, 263-273.

[13] K. Kannan and M. Udayakumar, NOx and HC emission control using water emulsified diesel in single cylinder diesel engine, Journal of Engineering and Applied Sciences, 4 (8), 2019, 59-62.

[14] X. Wang, Y. Qian, Q. Zhou, and X. Lu, Modulated diesel fuel injection strategy for efficient-clean utilization of low-grade biogas, Applied Thermal Engineering, 107, 2016, 844-852.

[15] Y. Qian, Y. Zhang, X. Wang, and X. Lu, Particulate matter emission characteristics of a reactivity controlled compression ignition engine fueled with biogas/diesel dual fuel, Journal of Aerosol Science, 113 (August), 2017, 166-177.

[16] A. Kakaee, P. Rahnama, and A. Paykani, Influence of fuel composition on combustion and emissions characteristics of natural gas/diesel RCCI engine, Journal of Natural Gas Science and Engineering, 25 (x), 2015, 58-65.

[17] K. E. Niemeyer, S. R. Daly, W. J. Cannella, and C. L. Hagen, Investigation of the LTC fuel performance index for oxygenated reference fuel blends, Fuel, 155 (x), 2015, 14-24.

[18] A. K. Agarwal, A. P. Singh, R. K. Maurya, Evolution, challenges and path forward for low temperature combustion engines, Progress in Energy and Combustion Science, 61, 2017, 1-56.

[19] S. Imtenan, M. Varman, H. H. Masjuki, M. A. Kalam, H. Sajjad, M. I. Arbab, I. M. Rizwanul Fattah, Impact of low temperature combustion attaining strategies on diesel engine emissions for diesel and biodiesels: A review, Energy Conversion and Management, 80 (x), 2014, 329-356.

[20] R. D. Reitz and G. Duraisamy, Review of high efficiency and clean reactivity controlled compression ignition (RCCI) combustion in internal combustion engines, Progress in Energy and Combustion Science, 46, 2015, 12-71.

[21] I. B. Dalha., M. A. Said, Z. A. A. Karim, and F. Firmansyah, Strategies and methods of RCCI combustion: A review, AIP Conference Proceedings 2035, 2018 (030006), 030006$1-5$. 
[22] I. B. Dalha, M. A. Said, Z. A. Abdul Karim, A. A. A. Rashid, Firmansyah, E. Z. Z. Abidin, M. A. Ismael, Reactivity Controlled Compression Ignition: An Advanced Combustion Mode for Improved Energy Efficiency, in Energy Efficiency in Mobility Systems, Springer, 2020, 101-126.

[23] Y. Wang, M. Yao, T. Li, W. Zhang, and Z. Zheng, A parametric study for enabling reactivity controlled compression ignition $(\mathrm{RCCI})$ operation in diesel engines at various engine loads, Applied Energy, 175, 2016, 389-402.

[24] C. Kavuri, J. Paz, and S. L. Kokjohn, A comparison of Reactivity Controlled Compression Ignition (RCCI) and Gasoline Compression Ignition (GCI) strategies at high load, low speed conditions, Energy Conversion and Management, 127, 2016, 324-341.

[25] A. Boretti, "Numerical modeling of a jet ignition direct injection (JI DI) LPG engine, International Journal of Engineering and Technology Innovation, 7 (1), 2017, 24-38.

[26] A. M. Ithnin, M. A. Ahmad, M. A. A. Bakar, S. Rajoo, and W. J. Yahya, Combustion performance and emission analysis of diesel engine fuelled with water-in-diesel emulsion fuel made from low-grade diesel fuel, Energy Conversion and Management, 90, 2015, $375-382$.

[27] E. Bocci, M. Sisinni, M. Moneti, L. Vecchione, D. C. A, and M. Villarini, State of art of small scale biomass gasification power systems: a review of the different typologies, Energy Procedia, 45, 2014, 247-256.

[28] M. E. A. Fahd, Y. Wenming, P. S. Lee, S. K. Chou, and C. R. Yap, Experimental investigation of the performance and emission characteristics of direct injection diesel engine by water emulsion diesel under varying engine load condition, Applied Energy, 102, 2013, 1042-1049.

[29] M. Wissink and R. D. Reitz, Direct dual fuel stratification, a path to combine the benefits of RCCI and PPC, SAE International Journal of Engines, 8 (2), 2015, 2015-01-0856.

[30] B. K. Debnath, U. K. Saha, and N. Sahoo, An experimental way of assessing the application potential of emulsified palm biodiesel toward alternative to diesel, Journal of Engineering for Gas Turbines and Power, 136 (2) 2014, 1-12. 